\title{
Fungos micorrízicos arbusculares em solos de área de mineração de bauxita em reabilitação(1)
}

\author{
Rogério Melloni( ${ }^{(2)}$, José Oswaldo Siqueira ${ }^{(3)}$ e Fátima Maria de Souza Moreira(3)
}

\begin{abstract}
Resumo - Apesar de a mineração de bauxita causar grandes alterações nas características do solo, com efeitos negativos nas micorrizas arbusculares, os efeitos da reabilitação de áreas mineradas sobre os fungos micorrízicos arbusculares (MA) e sua simbiose são pouco conhecidos. O objetivo deste trabalho foi avaliar a ocorrência, diversidade e eficiência dos fungos MA, em áreas de mineração de bauxita, com diferentes tipos de vegetação e idades de reabilitação. Amostras de solo da rizosfera foram coletadas para analisar o micélio fúngico extrarradicular, o número de esporos, a riqueza e diversidade de fungos MA e para avaliar a colonização micorrízica e eficiência simbiótica de populações fúngicas. A mineração afetou negativamente os fungos MA, sendo a recuperação destes mais relacionada com o tipo de vegetação do que com o tempo de reabilitação da área. Foram encontradas as espécies: Gigaspora margarita, Gigaspora sp., Paraglomus occultum, Glomus sp., Entrophospora colombiana e Acaulospora scrobiculata. A ocorrência desses fungos foi favorecida pela presença de gramíneas e de bracatinga. Embora Eucalyptus saligna não seja um bom hospedeiro para os fungos MA, quando associado a sub-bosque bem desenvolvido e diverso, contribuiu para a recuperação dos fungos. As populações fúngicas isoladas de áreas com braquiária e feijão-guandu ou de bracatinga com capim-gordura apresentaram elevada eficiência para o feijoeiro, mostrando que é possível recuperar a função deste grupo de microrganismos utilizando diferentes tipos de vegetação. Estes isolados apresentam potencial de utilização em programas de reabilitação de solos minerados.
\end{abstract}

Termos para indexação: vegetação, simbiose, simbionte, recuperação do solo.

\section{Arbuscular mycorrhizal fungi in soils of bauxite mining area under rehabilitation}

Abstract - Despite the fact that bauxite mining activity promotes changes in soil characteristics, with negative effects on arbuscular mycorrhizas (AM), the effects of rehabilitation on AM fungi and their symbiosis are unknown. The purpose of this study was to evaluate the occurrence, diversity and efficiency of AM fungi, in bauxite mining areas, with different vegetation types and rehabilitation ages. Rhizosphere soil samples were collected for evaluations of extraradical mycelium, spore density, richness and diversity of AM fungi and to evaluate root colonization and symbiotic efficiency of fungal populations. Mining activity had negative effects on AM fungi and the AM recovering was more related to vegetation types than to areas rehabilitation age. Six species were found: Gigaspora margarita, Gigaspora sp., Paraglomus occultum, Glomus sp., Entrophospora colombiana and Acaulospora scrobiculata. AM fungi occurrence was favored by both grasses and Mimosa scabrella. Although Eucalyptus saligna was not a good host for these fungi, its presence associated with a well developed and diverse understore contributed for the recovering of AM fungi. The fungal populations isolated from areas with Brachiaria decumbens and Cajanus cajan and from Mimosa scabrella and Melinis minutiflora were highly efficient for bean plants growth, showing that it is possible to recover the function of AM fungi using different vegetation types. These AM fungi present a high potential of utilization for the rehabilitation of mining disturbed areas.

Index terms: vegetation, symbiosis, symbionts, reclamation.

(1) Aceito para publicação em 30 de setembro de 2002. Extraído da tese de doutorado apresentada pelo primeiro autor à Universidade Federal de Lavras, Lavras, MG. Parcialmente financiado pelo convênio Alcoa Alumínio S/A de Poços de Caldas (MG) e Fapemig.

(2) Universidade Federal de Itajubá, Instituto de Engenharia Mecânica, Dep. de Mecânica, Caixa Postal 50, CEP 37500-903 Itajubá, MG. E-mail: rmelloni@iem.efei.br

(3)Universidade Federal de Lavras, Dep. de Ciência do Solo, Caixa Postal 37, CEP 37200-000 Lavras, MG. Bolsista do CNPq. E-mail: siqueira@ufla.br, fmoreira@ufla.br

\section{Introdução}

Quando em simbiose com plantas, os fungos micorrízicos arbusculares (MA) otimizam a tolerância das plantas a estresses abióticos (Johnson \& Pfleger, 1992), a agregação do solo (Miller \& Jastrow, 1992) e a utilização de água e nutrientes do solo em virtude da maior absorção pelo micélio extrarradicular (Smith \& Read, 1997). Isso possibilita maior vantagem competitiva das plantas micorrizadas e facilita o 
estabelecimento e sucessão da vegetação, o que contribui para a reabilitação de áreas degradadas.

A atividade de mineração exerce grande impacto adverso sobre os organismos e processos do solo, inclusive sobre os fungos MA. Por serem biotróficos obrigatórios, portanto dependentes da presença de plantas hospedeiras para completarem seu ciclo de vida, os fungos MA sofrem grande redução quando os ecossistemas são submetidos a interferências antrópicas intensas que destroem a vegetação, como ocorre em áreas de mineração.

Diversos estudos realizados em solos dessas áreas, como de mineração de carvão, nos EUA (Kiernan et al., 1983; Walland \& Allen, 1987) e de magnesita e carvão, na Índia (Raman et al., 1993; Mehrotra, 1998), mostraram redução do número de propágulos desses fungos e baixa colonização das plantas locais. A substituição da camada superficial do solo original por outra com baixo número de propágulos, o longo tempo de armazenamento desta camada superficial antes da reabilitação (White et al., 1989), a destruição física da rede micelial (Jasper et al., 1992), a retirada da vegetação, a exposição dos propágulos a extremos de umidade e temperatura (Braunberg et al., 1996; McGonigle \& Miller, 1999) e baixos valores de $\mathrm{pH}$ (Mehrotra, 1998) reduzem a densidade e diversidade desses fungos. A implantação da vegetação e conseqüente sucessão decorrente da reabilitação podem reverter, pelo menos em parte, os impactos da mineração sobre esses fungos. A diversidade dos fungos MA se relaciona com a diversidade da vegetação (Heijden et al., 1998), sendo, portanto, de grande importância à estruturação, desenvolvimento e sustentabilidade da comunidade vegetal e reabilitação dos solos minerados (Mehrotra, 1998). No entanto, os efeitos da reabilitação em áreas de mineração de bauxita sobre esses fungos são pouco conhecidos.

O objetivo deste trabalho foi avaliar a ocorrência, diversidade e eficiência de fungos MA, em áreas de mineração de bauxita, com diferentes tipos de vegetação e idades de reabilitação.

\section{Material e Métodos}

O presente estudo foi realizado em áreas da Alcoa Alumínio S/A, Poços de Caldas, MG, em dois ambientes distintos, de serra e de campo. De acordo com o histórico quanto à mineração e estágio de reabilitação, e tipo de solo, selecionaram-se 17 áreas em Cambissolo distrófico para as amostragens. Foram selecionadas oito áreas no campo, com vegetação original típica de campo tropical, composta por espécies herbáceas e arbustivas, e nove áreas na serra mais montanhosa e com cobertura vegetal original tipo capoeira e mata. As áreas mineradas foram reabilitadas, mediante a semeadura de gramíneas e leguminosas herbáceas e plantios de mudas de bracatinga, de espécies arbóreas nativas e de Eucalyptus saligna, atualmente com diferentes idades (Tabela 1). As amostras de solo e de raízes de cada área foram coletadas no inverno, no verão e na primavera, dentro de três transectos de $4 \times 25 \mathrm{~m}$, na profundidade de $0-10 \mathrm{~cm}$, num total de três amostras compostas por área, formadas por dez subamostras cada. Cada área foi considerada um tratamento (com três repetições formadas pelas três amostras compostas), e utilizou-se o delineamento inteiramente ao acaso, dentro de cada época de amostragem.

Nas amostras de solo coletadas no inverno e verão, determinaram-se micélio extrarradicular ativo e total de fungos do solo (Melloni \& Cardoso, 1999); número total de esporos, após separação por peneiramento úmido (Gerdemann \& Nicolson, 1963), identificação (Schenck \& Pérez, 1987) e riqueza de espécies (número de espécies de fungos MA encontradas na amostra). Posteriormente, avaliaram-se o número e abundância relativa de cada espécie de fungo MA, para determinação do índice de diversidade (H') de Shannon-Weaver. Porções de raízes presentes nas três amostras compostas de solo de cada área foram reunidas, clarificadas e coradas, para a avaliação da colonização micorrízica.

Com as amostras de solo coletadas no verão, foram realizados três ensaios em casa de vegetação. No primeiro, a multiplicação dos fungos MA foi avaliada em condições controladas, conforme Brundrett et al. (1996), utilizandose como espécies de plantas-isca Brachiaria ruziziensis (capim-congo) e Neonotonia wightii (soja-perene) semeadas diretamente no solo das áreas, em vasos contendo $3 \mathrm{~kg}$ de solo de cada área. Essa quantidade de amostra de solo foi obtida pela reunião de três amostras compostas por área, num total de um vaso por área. O solo dessas amostras foi corrigido com calcário dolomítico para elevar a saturação por bases a $70 \%$ e adubado com $50 \mathrm{mg} \mathrm{kg}^{-1}$ de $\mathrm{P}\left(\mathrm{KH}_{2} \mathrm{PO}_{4}\right)$, $100 \mathrm{mg} \mathrm{kg}^{-1}$ de $\mathrm{K}\left(\mathrm{K}_{2} \mathrm{SO}_{4}\right), 15 \mathrm{mg} \mathrm{kg}^{-1}$ de $\mathrm{S}\left(\mathrm{K}_{2} \mathrm{SO}_{4}\right)$, $0,1 \mathrm{mg} \mathrm{kg}^{-1}$ de $\mathrm{Mo}\left(\mathrm{HMoO}_{4} \cdot \mathrm{H}_{2} \mathrm{O}\right), 5 \mathrm{mg} \mathrm{kg}^{-1}$ de $\mathrm{Zn}$ $\left(\mathrm{ZnSO}_{4} \cdot 7 \mathrm{H}_{2} \mathrm{O}\right), 1,5 \mathrm{mg} \mathrm{kg}^{-1}$ de $\mathrm{Cu}\left(\mathrm{CuCl}_{2} \cdot 2 \mathrm{H}_{2} \mathrm{O}\right)$ e $0,5 \mathrm{mg} \mathrm{kg}^{-1}$ de $\mathrm{B}\left(\mathrm{H}_{3} \mathrm{BO}_{3}\right)$. As plantas foram cultivadas por 13 meses para multiplicação de propágulos e a seguir, os esporos foram extraídos por peneiramento úmido, contados e identificados por espécie. 
No segundo ensaio, com delineamento inteiramente ao acaso e três repetições por área (cada amostra composta equivaleu a uma repetição), cultivou-se uma planta de caupi (Vigna unguiculata L. cv. Mulato) por vaso de PVC de 1 L de amostra de solo até o início do florescimento (47 dias), quando se avaliou colonização micorrízica. Efetuaram-se a correção e adubação das amostras de solo conforme descrito anteriormente. No terceiro ensaio, para avaliar a eficiência de populações de fungos MA das áreas, empregou-se o feijoeiro (Phaseolus vulgaris L. cv. Carioca) como planta-teste em vasos com 1,5 kg de amostras de Latossolo Vermelho-Escuro distrófico, fumigado (brometo de metila $98 \%$, na dose de $263 \mathrm{~cm}^{3} \mathrm{~cm}^{-3}$ ). O solo dessas amostras foi corrigido com calcário dolomítico para elevar a saturação por bases a $60 \%$ e adubado com $50 \mathrm{mg} \mathrm{kg}^{-1} \mathrm{de}$ $\mathrm{P}\left(\mathrm{KH}_{2} \mathrm{PO}_{4}\right), 20 \mathrm{mg} \mathrm{kg}^{-1}$ de S $\left[\left(\mathrm{NH}_{4}\right)_{2} \mathrm{SO}_{4}\right], 18 \mathrm{mg} \mathrm{kg}^{-1} \mathrm{de}$ $\mathrm{N}\left[\left(\mathrm{NH}_{4}\right)_{2} \mathrm{SO}_{4}\right], 63 \mathrm{mg} \mathrm{kg}^{-1}$ de $\mathrm{K}\left(\mathrm{KH}_{2} \mathrm{PO}_{4}\right), 0,1 \mathrm{mg} \mathrm{kg}^{-1}$ de $\mathrm{Mo}\left(\mathrm{HMoO}_{4} \cdot \mathrm{H}_{2} \mathrm{O}\right), 5 \mathrm{mg} \mathrm{kg}^{-1}$ de $\mathrm{Zn}\left(\mathrm{ZnSO}_{4} \cdot 7 \mathrm{H}_{2} \mathrm{O}\right)$, $1,5 \mathrm{mg} \mathrm{kg}^{-1}$ de $\mathrm{Cu}\left(\mathrm{CuCl}_{2} \cdot 2 \mathrm{H}_{2} \mathrm{O}\right), 0,5 \mathrm{mg} \mathrm{kg}^{-1}$ de $\mathrm{B}$ $\left(\mathrm{H}_{3} \mathrm{BO}_{3}\right)$. Utilizou-se o delineamento inteiramente ao acaso e três repetições por área (cada repetição equivaleu a uma amostra composta) quando da inoculação das plantas com esporos de fungos MA. Para isso, foram utilizados 200 esporos extraídos de amostra composta de solo de cada área, antes da multiplicação, aplicados abaixo das raízes das plântulas de feijoeiro, no transplantio. Em vasos adicionais, aplicaram-se 200 esporos de Glomus etunicatum Becker \& Gerdemann, extraídos de vasos de cultivo com Brachiaria decumbens, para servir como referência de eficiência; além de um controle, sem inoculação, como tratamentos adicionais. As plantas foram colhidas 51 dias após o transplantio para determinação da matéria seca da parte aérea (MSPA) e da colonização micorrízica. A eficiência relativa (\%) de produção de MSPA foi calculada considerando aquela produzida pelo feijoeiro não inoculado (testemunha) como 100.

Nas amostras de solo coletadas na primavera, avaliouse o número mais provável (NMP) de propágulos de fungos MA, conforme Souza \& Guerra (1998). A mistura diluente foi preparada com amostras de um Latossolo Vermelho-Escuro distrófico e areia $(1: 1 \mathrm{v} / \mathrm{v})$, autoclavada por duas vezes, em dias alternados, e secadas em estufa a $105^{\circ} \mathrm{C}$. A análise química dessas amostras revelou os seguintes resultados: $\mathrm{pH}, 5,7$; $\mathrm{P}$ (Mehlich1), $1 \mathrm{mg} \mathrm{dm}^{-3}$; P resina, 3,2 $\mathrm{mg} \mathrm{dm}^{-3} ; \mathrm{K}, 27 \mathrm{mg} \mathrm{dm}^{-3}$; Ca, 1,3 $\mathrm{cmol}_{\mathrm{c}} \mathrm{dm}^{-3}$; $\mathrm{Mg}, 1,1 \mathrm{cmol}_{\mathrm{c}} \mathrm{dm}^{-3} ; \mathrm{Al}, 0 \mathrm{cmol}_{\mathrm{c}} \mathrm{dm}^{-3} ; \mathrm{Zn}, 0,6 \mathrm{mg} \mathrm{kg}^{-1} ; \mathrm{Cu}$, $0,6 \mathrm{mg} \mathrm{kg}^{-1} ; \mathrm{Mn}, 22,0 \mathrm{mg} \mathrm{kg}{ }^{-1} ; \mathrm{Fe}, 10,8 \mathrm{mg} \mathrm{kg}^{-1} ; \mathrm{S}$, $4,3 \mathrm{mg} \mathrm{kg}^{-1} \mathrm{e} \mathrm{V}, 55 \%$. O P foi adicionado mensalmente e os demais nutrientes, quinzenalmente, via solução nutritiva (Souza \& Guerra, 1998). Com uma amostra de solo de cada área (amostra-teste), prepararam-se diluições (1:4) até a diluição $4^{-7}$, empregando-se $120 \mathrm{~g}$ de substrato em cada vaso de plástico de $200 \mathrm{~mL}$ e quatro repetições por diluição, semeando-se, em seguida, painço (Panicum miliaceum). Após 52 dias, coletaram-se as raízes para verificação da colonização micorrízica, registrando-se ausência ou presença de estruturas fúngicas para o cálculo do número mais provável (NMP).

Com exceção do número de esporos obtidos dos vasos com amostras de solo cultivadas com plantas-isca, colonização micorrízica de plantas locais e H', onde cada área foi representada por uma amostra, todos os demais resultados foram submetidos à análise de variância pelo teste F.

Tabela 1. Características principais das áreas amostradas, em dois ambientes (campo e serra) de solos minerados e em diferentes tamanhos e idades aproximadas.

\begin{tabular}{|c|c|c|c|}
\hline Áreas & Características principais da área amostrada & Idade & $\begin{array}{c}\text { Tamanho } \\
\text { (ha) }\end{array}$ \\
\hline \multicolumn{4}{|c|}{ Campo } \\
\hline 1 & Recém-minerada e não reabilitada & 0 & 4,98 \\
\hline 2 & Recém-minerada, coberta por braquiária (Brachiaria decumbens) e feijão-guandu (Cajanus cajan) & 6 meses & 4,98 \\
\hline 3 & Plantio homogêneo de eucalipto (Eucalyptus saligna) & 3 anos & 4,22 \\
\hline 4 & Capim-azevém (Lolium multiflorum) e Eupathorium sp. (Asteraceae) & 4 anos & 1,33 \\
\hline 5 & Capim-gordura (Melinis minutiflora), em sucessão. Presença de espécies nativas como bracatinga & 10 anos & 1,90 \\
\hline 6 & Eucalipto (Eucalyptus saligna) e serapilheira espessa & 16 anos & 4,69 \\
\hline 7 & Bracatinga (Mimosa scabrella) e sub-bosque bem desenvolvido (capim-gordura, alecrim) & 19 anos & 1,73 \\
\hline 8 & Referência, com espécies graminóides e arbustivas (sem alteração antrópica) & - & 11,00 \\
\hline \multicolumn{4}{|c|}{ Serra } \\
\hline 9 & Recém-minerada e não reabilitada & 0 & 4,85 \\
\hline 10 & Recém-minerada, coberta por capim-gordura, feijão-guandu e espécies arbóreas nativas & 6 meses & 4,85 \\
\hline 11 & Braquiária, feijão-guandu e espécies arbóreas nativas & 2 anos & n.d. ${ }^{(1)}$ \\
\hline 12 & Bracatinga e sub-bosque coberto por capim-gordura & 6 anos & 2,55 \\
\hline 13 & Mata de nativas e sub-bosque bem desenvolvido, com serapilheira adicionada & 10 anos & 2,18 \\
\hline 14 & Bracatinga e vegetação rasteira e arbustiva, processo de sucessão lento & 14 anos & 8,89 \\
\hline 15 & Eucalipto (E. saligna) e sub-bosque bem desenvolvido (gramíneas e arbustos) & 16 anos & 17,42 \\
\hline 16 & Mata de nativas, incluindo bracatinga, sub-bosque fechado, serapilheira espessa, troncos caídos & 18 anos & 3,85 \\
\hline 17 & Referência, mata fechada com espécies arbóreas (sem alteração antrópica) & - & 57,23 \\
\hline
\end{tabular}


As médias foram comparadas pelo teste de Duncan a 5\% de probabilidade, dentro de cada ambiente (campo e serra), utilizando-se o programa estatístico SANEST (Zonta et al., 1984). Antes de serem analisados, os dados de porcentagem de colonização micorrízica foram transformados em $\operatorname{arco~seno~}(\mathrm{x} / 100)^{1 / 2}$ e os de número de esporos em $\mathrm{x}^{1 / 2}$.

\section{Resultados e Discussão}

Apesar de os valores para comprimento de micélio, número de esporos e diversidade de fungos MA serem maiores em amostras de solo coletadas no verão em relação àquelas no inverno, o comportamento destas variáveis nas diferentes áreas de mineração foi muito semelhante. Por isso, somente os dados relativos à amostragem de verão são apresentados neste trabalho (Tabela 2). A mineração reduziu o micélio de fungos MA do solo. A porcentagem de micélio ativo foi menor que 5\% do micélio total em todas as áreas e, como não se verificou relação com a idade de reabilitação, somente os dados de micélio total foram apresentados. A intensa redução causada pela mineração foi também observada em áreas agrícolas submetidas a cultivo convencional, no Canadá, como conseqüência do intenso revolvimento do solo e da quebra da rede micelial (Kabir et al., 1997).

No entanto, no presente trabalho, a revegetação do solo pôde recuperar o micélio fúngico e, aos seis meses de reabilitação com braquiária ou capim-gordura e feijão-guandu, verificaram-se aumentos consideráveis no micélio total, sendo que as áreas com bracatinga, tanto no campo quanto na serra, apresentaram valores superiores aos das referências. Nas áreas com eucalipto, verificaram-se baixos valores de micélio no campo, enquanto na serra, estes não diferiram da referência. Isto porque nesta condição o eucalipto apresentava sub-bosque bem desenvolvido e diverso (Tabela 1), o que pode ter contribuído para o desenvolvimento dos fungos MA (Heijden et al., 1998).

Tabela 2. Micélio total, número de esporos, espécies de fungos micorrízicos arbusculares encontradas e respectiva freqüência de ocorrência em amostras de campo, índice de diversidade de Shannon-Weaver (H') e colonização micorrízica de espécies recuperadas diretamente das amostras de solo em diferentes áreas ${ }^{(1)}$.

\begin{tabular}{|c|c|c|c|c|c|}
\hline Áreas $^{(2)}$ & $\begin{array}{l}\text { Micélio } \\
\text { total }\left(\mathrm{m} \mathrm{g}^{-1}\right)\end{array}$ & $\begin{array}{c}\text { Esporos } \\
\left(\mathrm{n}^{\circ} 50 \mathrm{~mL}^{-1}\right)\end{array}$ & $\begin{array}{l}\text { Espécies encontradas nas amostras de } \\
\text { campo }^{(3)} \text { e freqüência }{ }^{(4)} \text { de ocorrência }(\%)\end{array}$ & $\mathrm{H}^{\prime}$ & $\begin{array}{c}\text { Colonização } \\
\text { micorrízica }(\%)\end{array}$ \\
\hline \multicolumn{6}{|c|}{ Campo } \\
\hline 1 & $0 \mathrm{c}$ & $15 \mathrm{e}$ & Glsp (80), Acsc (20) & 0,5 & - \\
\hline 2 & $13 \mathrm{c}$ & $67 \mathrm{~cd}$ & Gima (5), Pocc (20), Ecol (31), Gisp (5), Glsp (27), Acsc (12) & 1,6 & 4 \\
\hline 3 & $16 \mathrm{c}$ & $121 \mathrm{bc}$ & Gima (27), Pocc (20), Ecol (8), Gisp (3), Glsp (37), Acsc (5) & 1,5 & 4 \\
\hline 4 & $25 \mathrm{bc}$ & $240 \mathrm{a}$ & Gima (8), Pocc (12), Ecol (7), Gisp (14), Glsp (48), Acsc (11) & 1,4 & 21 \\
\hline 5 & $47 \mathrm{a}$ & $218 \mathrm{ab}$ & Gima (5), Pocc (10), Ecol (18), Gisp (1), Glsp (47), Acsc (19) & 1,4 & 10 \\
\hline 6 & $15 \mathrm{c}$ & 41de & Gima (3), Pocc (14), Ecol (22), Gisp (3), Glsp (32), Acsc (26) & 1,5 & 1 \\
\hline 7 & $41 \mathrm{ab}$ & 261a & Gima (1), Pocc (4), Ecol (3), Gisp (1), Glsp (75), Acsc (16) & 0,8 & 9 \\
\hline 8 & $25 \mathrm{bc}$ & $77 \mathrm{~cd}$ & Gima (4), Pocc (20), Ecol (14), Gisp (2), Glsp (47), Acsc (13) & 1,4 & 2 \\
\hline \multicolumn{6}{|c|}{ Serra } \\
\hline 9 & $0 \mathrm{c}$ & $4 \mathrm{~d}$ & $\operatorname{Ecol}(25)$, Glsp (50), Acsc (25) & 1,0 & - \\
\hline 10 & $10 \mathrm{c}$ & $75 \mathrm{c}$ & Gima (8), Pocc (4), Ecol (7), Gisp (2), Glsp (73), Acsc (5) & 0,9 & 2 \\
\hline 11 & $32 b$ & $226 a b$ & Gima (1), Pocc (18), Ecol (27), Gisp (3), Glsp (25), Acsc (27) & 1,5 & 5 \\
\hline 12 & $60 \mathrm{a}$ & $384 \mathrm{a}$ & Gima (1), Pocc (38), Ecol (14), Gisp (2), Glsp (13), Acsc (32) & 1,4 & 11 \\
\hline 13 & $40 \mathrm{~b}$ & $208 \mathrm{abc}$ & Gima (2), Pocc (39), Ecol (4), Gisp (2), Glsp (37), Acsc (16) & 1,3 & 26 \\
\hline 14 & $44 a b$ & $149 \mathrm{bc}$ & Gima (2), Pocc (4), Ecol (12), Gisp (1), Glsp (73), Acsc (8) & 0,9 & 21 \\
\hline 15 & $46 a b$ & $178 \mathrm{bc}$ & Gima (3), Pocc (19), Ecol (18), Glsp (39), Acsc (21) & 1,4 & 8 \\
\hline 16 & $36 b$ & $181 \mathrm{bc}$ & Gima (3), Pocc (6), Ecol (7), Gisp (1), Glsp (65), Acsc (18) & 1,1 & 11 \\
\hline 17 & $33 b$ & $391 \mathrm{a}$ & Gima (1), Pocc (3), Ecol (3), Gisp (1), Glsp (88), Acsc (4) & 0,5 & 7 \\
\hline
\end{tabular}

${ }^{(1)}$ Médias seguidas por letras distintas, na coluna, diferem entre si pelo teste de Duncan a 5\% de probabilidade. (2) 1 : recém-minerada e não reabilitada do campo; 2: recém-minerada e coberta por braquiária e feijão-guandu com seis meses; 3: eucalipto (E. saligna) com três anos; 4: capim-azevém e Eupathorium sp. com quatro anos; 5: capim-gordura e espécies nativas com 10 anos; 6: eucalipto e serapilheira espessa com 16 anos; 7: bracatinga e sub-bosque desenvolvido com capim-gordura e alecrim, e com 19 anos; 8: referência do campo; 9: recém-minerada e não reabilitada da serra; 10: recém-minerada, coberta por capim-gordura, feijão-guandu e nativas com seis meses; 11: braquiária, feijão-guandu e nativas com dois anos; 12: bracatinga e sub-bosque coberto por capim-gordura com seis anos; 13: mata de nativas e sub-bosque desenvolvido com adição de serapilheira e com 10 anos; 14: bracatinga e vegetação rasteira e arbustiva com 14 anos; 15: eucalipto (E. saligna) e sub-bosque desenvolvido com 16 anos; 16 : mata de nativas, incluindo bracatinga, sub-bosque fechado e serapilheira espessa, com 18 anos; 17: referência da serra. ${ }^{(3)}$ Acsc (Acaulospora scrobiculata), Ecol (Entrophospora colombiana), Gima (Gigaspora margarita), Gisp (Gigaspora sp.), Glsp (Glomus sp.), Pocc (Paraglomus bccultum). ${ }^{(4)}$ Relação porcentual entre número de esporos de cada espécie e o total de esporos obtidos por área, representada pelos números entre parênteses. 
A mineração afetou igualmente a densidade de esporos, que aumentou por reabilitação (Tabela 2). Este resultado difere do obtido por Caproni (2001), em solos de área de mineração de bauxita em Porto Trombetas, PA, com e sem reposição da camada superficial orgânica, revegetados com espécies arbóreas pioneiras por 2 a 16 anos. Nestes solos não se verificou relação entre número de esporos de fungos MA e idade de revegetação. Naquele estudo, os valores de densidade de esporos estiveram entre 1.660 e 2.101 esporos por $50 \mathrm{~mL}^{-1}$, muito superior à obtida em Poços de Caldas, MG, mesmo nas áreas com gramíneas (braquiária, capim-azevém ou capim-gordura) e com bracatinga em idade avançada, onde se obteve densidade máxima ao redor de 265 esporos por $50 \mathrm{~mL}^{-1}$.

Carneiro et al. (1995), avaliando os efeitos de Brachiaria decumbens na revegetação de solos degradados, observaram, além da proteção física do solo, aumento da biomassa de raízes, enriquecimento do solo em carbono e aumento de $400 \%$ na densidade de esporos no solo, quando inoculada com G. etunicatum, confirmando ser esta espécie de gramínea boa multiplicadora desses fungos e importante na reabilitação de áreas mineradas. Cuenca et al. (1998), em solos degradados da Venezuela, também verificaram que a revegetação com braquiária proporcionou aumento da densidade de esporos de fungos MA, de 18 a 471 vezes, com relação a solos degradados, não revegetados.

No presente trabalho, as áreas recém-mineradas e com plantas de eucalipto com 16 anos (campo) apresentaram os menores valores de densidade de esporos (15 e 41 esporos por $50 \mathrm{~mL}^{-1}$, respectivamente), o que concorda com os resultados já apresentados em relação ao comprimento de micélio no solo, e com os relatados por Siqueira et al. (1989), em áreas de eucalipto do sudeste do Brasil (24 a 60 esporos por $50 \mathrm{~mL}^{-1}$ ), e por Mehrotra (1998), em áreas de mineração de carvão na Índia (cerca de 10 esporos por $50 \mathrm{~mL}^{-1}$ ). Portanto, o plantio adensado e homogêneo de eucalipto não possui ação amenizadora do impacto causado pela mineração sobre este grupo de microrganismos do solo nestas áreas.

Foram identificadas seis espécies de fungos MA nas amostras de solo das áreas de estudo: Gigaspora margarita Becker \& Hall, Gigaspora sp. Gerd. \&
Trappe, Paraglomus occultum Morton \& Redecker, Entrophospora colombiana Spain \& Schenck, Acaulospora scrobiculata Trappe e Glomus sp. Tulasne \& Tulasne (Tabela 2). Gigaspora sp. é representada por esporos grandes, maiores que $200 \mu \mathrm{m}$, coloração verde-claro, forma globosa a subglobosa, sem ornamentação na parede externa, paredes laminadas e forte reação ao reagente de Melzer, enquanto os esporos de Glomus sp. são pequenos, menores que $100 \mu \mathrm{m}$, coloração alaranjada a marrom, forma globosa a irregular, paredes laminadas e membranosas, fraca reação ao reagente de Melzer. Nenhum desses isolados pôde ser enquadrado nas espécies atualmente descritas. As características de Glomus sp. são semelhantes àquelas descritas para a espécie não classificada, que ocorreu em alta freqüência em solos degradados da Venezuela (Cuenca et al., 1998) e em solos de mineração de carvão na Índia (Mehrotra, 1998). O baixo número de espécies encontradas no presente trabalho foi igual ao relatado por Mehrotra (1998) em solos de mineração de carvão na Índia, revegetados há sete anos com diferentes espécies arbóreas. Porém, foi inferior ao obtido por Kiernan et al. (1983) em solos de áreas de mineração de carvão nos EUA, naturalmente revegetadas há mais de 30 anos (oito espécies), e por Raman et al. (1993) em solos de mineração de magnesita na Índia, sob revegetação espontânea, onde encontraram-se 13 espécies de fungos MA. Caproni (2001), em solos de área de mineração de bauxita em Porto Trombetas, obteve 57 espécies de fungos MA. Estas áreas, revegetadas com diferentes espécies arbóreas pioneiras por 2 a 16 anos, assim como observado nas áreas do presente trabalho, mostraram que a mineração de bauxita e os processos de revegetação não destruíram significativamente a diversidade das populações de fungos MA.

As diferenças nas condições edáficas e na cobertura vegetal interferiram na densidade e na riqueza de espécies de fungos MA nas áreas de mineração de bauxita estudadas (Tabela 2). Menor riqueza ocorreu nas áreas recém-mineradas, não sendo encontradas Gigaspora margarita, Gigaspora sp. e Paraglomus occultum em nenhuma delas. Glomus sp., Acaulospora scrobiculata e P. occultum foram as espécies de maior freqüência, enquanto aquelas do gênero Gigaspora, as menos freqüentes. 
Portanto, houve impacto negativo da interferência antrópica sobre os fungos MA. Entre as 57 espécies de fungos MA obtidas em área de mineração de bauxita de Porto Trombetas, Caproni (2001) isolou quatro das seis espécies descritas no presente trabalho (A. scrobiculata, E. colombiana, G. margarita e $P$. occultum), com maior e menor freqüência de espécies pertencentes às famílias Glomaceae e Gigasporaceae, respectivamente. Também em solos de mineração de carvão, na Índia, Mehrotra (1998) observou alta freqüência de Glomus sp. e A. scrobiculata. A ocorrência de Glomus sp., de Acaulospora scrobiculata e de Entrophospora colombiana nestas áreas sugere que esses fungos possuem mecanismos especiais de adaptação para sobrevivência nos solos minerados, fato também comentado por Mehrotra (1998). O maior tamanho dos esporos de Gigaspora pode ter dificultado a disseminação destes na área (Warner et al., 1987) e, assim, sua sobrevivência e restabelecimento em áreas onde a vegetação sofreu grande interferência.

O tempo de reabilitação das áreas não influenciou a diversidade de fungos MA (Tabela 2). No entanto, no presente trabalho, verificou-se que nas áreas da serra, a diversidade foi superior à encontrada para a referência neste mesmo ambiente. Além do efeito benéfico da revegetação com bracatinga, houve um efeito rápido do plantio de braquiária e feijão-guandu no campo, que com apenas seis meses, aumentou a diversidade três vezes em relação à área recém-minerada, com valores superiores aos das referências em ambos os ambientes de campo e serra. Cuenca et al. (1998) também obtiveram aumento da densidade de esporos e diversidade de fungos MA após revegetação com Brachiaria decumbens de solos degradados pela construção de rodovias, na Venezuela, mas a diversidade observada não atingiu o valor original de áreas não degradadas, ocorrendo perdas de espécies pertencentes aos gêneros Scutellospora e Gigaspora. Na colonização micorrízica avaliada nas amostras de raízes coletadas diretamente das áreas, verificaram-se baixos valores, mesmo nas áreas-referência (Tabela 2), indicando o baixo grau de micotrofismo das espécies vegetais nessas condições.

Nos vasos com espécies de plantas-isca (capim-congo e soja-perene), com exceção das áreas com reabilitação recente (com dois e seis anos, respectivamente), na serra, as demais áreas apresentaram tendência de ter maior densidade de esporos (Tabela 3) àquela obtida pela avaliação feita diretamente nas amostras de solo (Tabela 2). Destacaramse as áreas recém-mineradas do campo e serra, e com eucalipto no campo, em cujas amostras de solo observou-se esporulação abundante. Este resultado sugere que, mesmo com a atividade de mineração de bauxita em Poços de Caldas, a viabilidade e capacidade de multiplicação de esporos de fungos MA são mantidas, o que favorece a colonização de plantas durante a reabilitação.

No caso do eucalipto, apesar da baixa incidência de fungos MA revelada nas amostras, verificou-se grande esporulação quando raízes de espécies mais susceptíveis (capim-congo e soja-perene) estavam disponíveis. Nesses vasos, não se obtiveram espécies diferentes daquelas recuperadas nas amostras do campo, sendo as espécies dos gêneros Glomus e Paraglomus e $A$. scrobiculata as mais freqüentemente recuperadas. No entanto, a ausência em algumas áreas de espécies do gênero Gigaspora e E. colombiana (Tabela 3 ) indica condições ou hospedeiro desfavoráveis à esporulação dessas espécies. A calagem pode ter influenciado a riqueza de fungos MA, já que a acidez tem ação fungistática e esta é mais ativa para Glomus em relação à Gigaspora (Siqueira et al., 1989).

Verificou-se efeito positivo da reabilitação na colonização micorrízica do caupi, sem, entretanto, haver relação entre colonização e idade de reabilitação. Resultado semelhante foi observado por Walland \& Allen (1987), em solos de mineração de carvão, nos EUA, em diferentes estágios de reabilitação. Várias situações, principalmente aquelas com bracatinga e gramíneas no campo e serra, contribuíram para que raízes recuperadas diretamente das amostras de solo e de caupi apresentassem colonização micorrízica igual ou superior às das áreas das referências citadas. No entanto, entre as áreas em reabilitação, nas de plantio adensado e homogêneo de E. saligna do campo obtiveram-se os menores valores de colonização micorrízica, concordando com o baixo número de esporos e micélio de fungos MA obtidos. Apesar disso, nessa condição, observou-se alta diversida- 
de de fungos MA (Tabela 2), indicando que as populações nativas apresentam baixa infectividade para esta espécie arbórea.

Com relação ao NMP de propágulos de fungos MA, confirmou-se o efeito positivo da reabilitação (Tabela 3). Os maiores valores foram obtidos em solos reabilitados com braquiária, capim-gordura e bracatinga do campo e serra sem, contudo, haver relação direta com o tempo de reabilitação. Portanto, o tipo de vegetação presente é mais importante para aumentar a densidade de propágulos no solo que o tempo de reabilitação da área. Não foi verificada qualquer correlação entre NMP e micélio, ou esporos e colonização das raízes. Allen \& Allen (1980), estudando o efeito da reabilitação de solos de mineração de carvão, nos EUA, sobre os fungos (MA), também relataram fraca relação entre essas variáveis e nenhum efeito do tempo de reabilitação. Portanto, outros fatores como disponibilidade de nutrientes, matéria orgânica, textura e umidade do solo, genótipo de hospedeiros e, talvez, fontes e modos de dispersão de propágulos (Walland \& Allen, 1987) são fatores ecológicos determinantes da presença dos fungos MA em áreas mineradas.

A eficiência simbiótica de populações de fungos MA isoladas das áreas mineradas e avaliada em feijoeiro é mostrada na Tabela 4. Apesar da semelhança entre as populações do campo e serra, em termos de espécies dominantes (Tabela 2), a funcionalidade é diferente, com tendência das populações de fungos MA da serra serem mais eficientes do que as do campo. Os fungos das áreas de braquiária com feijão-guandu e de bracatinga com capim-gordura foram os mais eficientes, especialmente aqueles da

Tabela 3. Número de esporos, espécies de fungos MA encontradas nos vasos com plantas-isca, respectiva freqüência de ocorrência e índice de diversidade de fungos MA (H'), após 13 meses de multiplicação em Brachiaria ruziziensis e Neonotonia wightii, colonização micorrízica de caupi e número mais provável (NMP) de propágulos de fungos MA em amostras do campo cultivadas com Panicum miliaceum ${ }^{(1)}$.

\begin{tabular}{|c|c|c|c|c|c|}
\hline Áreas $^{(2)}$ & $\begin{array}{c}\text { Esporos } \\
\left(\mathrm{n}^{\mathrm{0}} 50 \mathrm{~mL}^{-1}\right)\end{array}$ & $\begin{array}{c}\text { Espécies encontradas em vasos com plantas-isca }^{(3)} \\
\text { e freqüência }{ }^{(4)} \text { de ocorrência }(\%)\end{array}$ & $\mathrm{H}^{\prime}$ & $\begin{array}{l}\text { Colonização } \\
\text { micorrízica de } \\
\text { caupi }(\%)\end{array}$ & $\begin{array}{c}\text { NMP de } \\
\text { propágulos } \\
\left(\mathrm{n}^{\circ} \mathrm{g}^{-1} \text { solo) }\right.\end{array}$ \\
\hline \multicolumn{6}{|c|}{ Campo } \\
\hline 1 & 327 & Pocc (68), Ecol (1), Gisp (14), Glsp (1), Acsc (16) & 0,9 & $7 \mathrm{~d}$ & 7,5 \\
\hline 2 & 280 & Gima (3), Pocc (37), Ecol (8), Gisp (14), Glsp (24), Acsc (14) & 1,6 & $23 \mathrm{c}$ & 313,3 \\
\hline 3 & 218 & Gima (8), Pocc (33), Ecol (2), Gisp (32), Glsp (14), Acsc (11) & 1,5 & $26 \mathrm{c}$ & 11,4 \\
\hline 4 & 546 & Pocc (20), Ecol (5), Gisp (31), Glsp (4), Acsc (40) & 1,3 & $69 \mathrm{a}$ & 106,3 \\
\hline 5 & 225 & Pocc (15), Ecol (4), Gisp (6), Glsp (62), Acsc (13) & 1,1 & $45 \mathrm{~b}$ & 240,4 \\
\hline 6 & 1.708 & Pocc (29), Ecol (68), Glsp (3) & 0,6 & $21 \mathrm{c}$ & 4,5 \\
\hline 7 & 983 & Gima (1), Pocc (63), Gisp (1), Glsp (27), Acsc (8) & 0,9 & $39 \mathrm{~b}$ & 621,7 \\
\hline 8 & 101 & Gima (2), Pocc (16), Ecol (1), Gisp (17), Glsp (46), Acsc (18) & 1,4 & $38 \mathrm{~b}$ & 42,5 \\
\hline \multicolumn{6}{|c|}{ Serra } \\
\hline 9 & 952 & Pocc (96), Ecol (1), Glsp (1), Acsc (2) & 0,2 & $0 \mathrm{c}$ & 0,0 \\
\hline 10 & 2.979 & Pocc (77), Ecol (16), Gisp (3), Glsp (2), Acsc (2) & 0,7 & $40 \mathrm{~b}$ & 39,3 \\
\hline 11 & 112 & Gima (1), Pocc (22), Ecol (5), Gisp (1), Glsp (26), Acsc (46) & 1,3 & $35 \mathrm{~b}$ & 157,9 \\
\hline 12 & 230 & Pocc (44), Ecol (5), Gisp (3), Glsp (11), Acsc (37) & 1,2 & $31 \mathrm{~b}$ & 115,4 \\
\hline 13 & 236 & Pocc (61), Ecol (1), Gisp (1), Glsp (35), Acsc (2) & 0,8 & $63 \mathrm{a}$ & 102,6 \\
\hline 14 & 303 & Pocc (41), Ecol (1), Gisp (1), Glsp (39), Acsc (18) & 1,1 & $31 \mathrm{~b}$ & 25,1 \\
\hline 15 & 222 & Pocc (48), Ecol (5), Glsp (37), Acsc (10) & 1,1 & $34 \mathrm{~b}$ & 50,6 \\
\hline 16 & 486 & Gima (1), Pocc (74), Gisp (2), Glsp (16), Acsc (7) & 0,8 & $48 \mathrm{ab}$ & 22,7 \\
\hline 17 & 419 & Pocc (12), Gisp (4), Glsp (82), Acsc (2) & 0,6 & $44 \mathrm{~b}$ & 11,2 \\
\hline \multicolumn{6}{|c|}{ 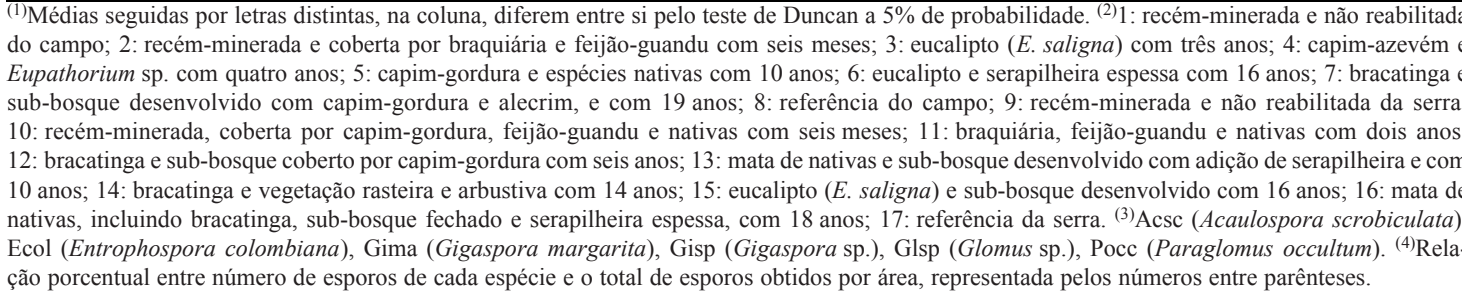 } \\
\hline
\end{tabular}


Tabela 4. Eficiência de inoculação de feijoeiro com esporos de fungos micorrízicos arbusculares extraídos diretamente das áreas estudadas, de campo e serra, ou de Glomus etunicatum.

\begin{tabular}{|c|c|c|c|}
\hline Áreas & Características principais da área amostrada & Idade & Eficiência $^{(1)}$ \\
\hline \multicolumn{4}{|c|}{ Campo } \\
\hline 1 & Recém-minerada e não reabilitada do campo & 0 & $-(2)$ \\
\hline 2 & Recém-minerada e coberta por braquiária e feijão-guandu & 6 meses & 122,4 \\
\hline 3 & Eucalipto (E. saligna) & 3 anos & 100,0 \\
\hline 4 & Capim-azevém e Eupathorium sp. & 4 anos & 69,4 \\
\hline 5 & Capim-gordura e espécies nativas & 10 anos & 204,7 \\
\hline 6 & Eucalipto e serapilheira espessa & 16 anos & 100,0 \\
\hline 7 & Bracatinga e sub-bosque desenvolvido com capim-gordura e alecrim & 19 anos & 97,6 \\
\hline 8 & Referência do campo & & 96,5 \\
\hline \multicolumn{4}{|c|}{ Serra } \\
\hline 9 & Recém-minerada e não reabilitada da serra & 0 & $-(2)$ \\
\hline 10 & Recém-minerada, coberta por capim-gordura, feijão-guandu e nativas & 6 meses & 116,5 \\
\hline 11 & Braquiária, feijão-guandu e nativas & 2 anos & 427,1 \\
\hline 12 & Bracatinga e sub-bosque coberto por capim-gordura & 6 anos & 298,8 \\
\hline 13 & Mata de nativas e sub-bosque desenvolvido com adição de serapilheira & 10 anos & 144,7 \\
\hline 14 & Bracatinga e vegetação rasteira e arbustiva & 14 anos & 116,5 \\
\hline 15 & Eucalipto (E. saligna) e sub-bosque desenvolvido & 16 anos & 134,1 \\
\hline 16 & Mata de nativas, incluindo bracatinga, sub-bosque fechado e serapilheira espessa & 18 anos & 158,8 \\
\hline 17 & Referência da serra & - & 96,5 \\
\hline Controle & & & 100,0 \\
\hline Glomus etunicatum & & & 408,2 \\
\hline
\end{tabular}

${ }^{(1)}$ Eficiência em relação à matéria seca da parte aérea de feijoeiro sem inoculação considerada 100. (2)Área não estudada pela falta de esporos de fungos micorrízicos arbusculares suficientes à inoculação.

serra, com eficiência relativa de $45 \%$ e $64 \%$, respectivamente, e com eficiência semelhante ao do fungo-referência G. etunicatum. A colonização do feijoeiro correlacionou-se positivamente com a matéria seca da parte aérea das plantas em relação aos isolados do campo $\left(0,88^{* *}\right)$ e da serra $(0,73 *)$, indicando que os fungos MA apresentaram forte influência no crescimento observado no feijoeiro. Nessas áreas, verificaram-se também altos índices de diversidade (Tabela 2) e NMP de propágulos (Tabela 3), mostrando que, apesar do impacto negativo da mineração nos fungos MA, é possível recuperar a função deste grupo de microrganismos utilizando diferentes tipos de revegetação.

\section{Conclusões}

1. A introdução de capim-gordura, capim-azevém, braquiária, feijão-guandu e bracatinga em solos de mineração de bauxita promove aumento do potencial de inóculo, diversidade e eficiência simbiótica de fungos MA, reduzindo ou eliminando o impacto causado pela interferência da mineração em relação às áreas-referência.

2. A recuperação dos fungos MA em área impactada pela mineração é mais relacionada com a vegetação introduzida do que com o tempo de reabilitação das áreas.
3. Embora o Eucalyptus saligna não seja um bom hospedeiro desses fungos, ocorre recuperação da densidade de propágulos em áreas com 16 anos de reabilitação com esta espécie, associada à presença de sub-bosque bem desenvolvido e diverso.

4. O índice de diversidade de Shannon-Weaver é favorecido pela reabilitação, mas não apresenta incremento após a multiplicação de propágulos em plantas-isca.

5. Nas áreas reabilitadas com braquiária e feijão-guandu ou com bracatinga e capim-gordura são encontrados isolados eficientes de fungos MA, os quais apresentam potencial de utilização na reabilitação de áreas de mineração de bauxita.

\section{Referências}

ALLEN, E. B.; ALLEN, M. F. Natural re-establishment of vesicular-arbuscular mycorrhizae following stripmine reclamation in Wyoming. Journal of Applied Ecology, Oxford, v. 17, n. 1, p. 139-147, Apr. 1980.

BRAUNBERG, P. G.; ABBOTT, L. K.; ROBSON, A. D. Infectivity of arbuscular mycorrhizal fungi after wetting and drying. New Phytologist, Oxford, v. 134, n. 4, p. 673 684, Dec. 1996.

BRUNDRETT, M. C.; BOUGHER, N.; DELL, B.; GROVE, T.; MALAJCZUK, N. Working with mycorrhizas in forestry and agriculture. Canberra: 
Australian Centre for International Agricultural Research, 1996. $374 \mathrm{p}$.

CAPRONI, A. L. Fungos micorrízicos arbusculares em áreas reflorestadas remanescentes da mineração de bauxita em Porto Trombetas/PA. 2001. 186 f. Tese (Doutorado em Fitotecnia) - Universidade Federal Rural do Rio de Janeiro, Seropédica, 2001.

CARNEIRO, M. A. C.; SIQUEIRA, J. O.; VALE, F. R. do; CURI, N. Limitação nutricional e efeito do pré-cultivo do solo com Brachiaria decumbens e da inoculação com Glomus etunicatum no crescimento de mudas de espécies arbóreas em solo degradado. Ciência e Prática, Lavras, v. 19, n. 3, p. 281-288, jul./set. 1995.

CUENCA, G.; ANDRADE, Z. de; ESCALANTE, G Diversity of glomalean spores from natural, disturbed and revegetated communities growing on nutrient-poor tropical soils. Soil Biology \& Biochemistry, Oxford, v. 30, n. 6, p. 711-719, June 1998.

GERDEMANN, J. W.; NICOLSON, T. H. Spores of mycorrhizal endogone species extracted from soil by wet sieving and decanting. Transactions of the British Mycological Society, Cambridge, Inglaterra, v. 46, n. 2 , p. 235-244, July 1963.

HEIJDEN, M. G. A. van der; KLIRONOMOS, J. N.; URSIC, M.; MOUTOGLIS, P.; STREITWOLF-ENGEL, R.; BOLLER, T.; WIEMKEN, A.; SANDERS, I. R. Mycorrhizal fungal diversity determines plant biodiversity, ecosystem variability and productivity. Nature, London, v. 396, p. 69-72, Nov. 1998.

JASPER, D. A.; ABBOTT, L. K.; ROBSON, A. D. Soil disturbance in native ecosystems the decline and recovery of infectivity of VA mycorrhizal fungi. In: READ, D. J.; LEWIS, D. H.; FITTER, A. H.; ALEXANDER, L. J. (Ed.). Mycorrhizas in ecosystems. Wallingford: CAB International, 1992. p. 151-155.

JOHNSON, N. C.; PFLEGER, F. L. Vesicular-arbuscular mycorrhizae and cultural stresses. In: BETHLENFALVAY, G. J.; LINDERMAN, R. G. (Ed.). Mycorrhizae in sustainable agriculture. Madison: American Society of Agronomy, 1992. p. 71-99.

KABIR, Z.; O'HALLORAN, I. P.; FYLES, J. W.; HAMEL, C. Seasonal changes of arbuscular mycorrhizal fungi as affected by tillage practices and fertilization: hyphal density and mycorrhizal root colonization. Plant and Soil, The Hague, v. 192, n. 2, p. 285-293, May 1997.

KIERNAN, J. M.; HENDRIX, J. W.; MARONEK, D. M. Endomycorrhizal fungi occurring on orphan strip mines in Kentucky. Canadian Journal of Botany, Ottawa, v. 61, n. 6, p. 1798-1803, June 1983.

McGONIGLE, T. P.; MILLER, M. H. Winter survival of extraradical hyphae and spores of arbuscular mycorrhizal fungi in the field. Applied Soil Ecology, Amsterdam, v. 12, n. 1, p. 41-50, Apr. 1999.

MEHROTRA, V. S. Arbuscular mycorrhizal associations of plants colonizing coal mine spoil in India. Journal of Agricultural Science, Cambridge, Inglaterra, v. 130, n. 2, p. 125-133, Mar. 1998.

MELLONI, R.; CARDOSO, E. J. B.N. Quantificação de micélio extrarradicular de fungos micorrízicos arbusculares em plantas cítricas - I: método empregado. Revista Brasileira de Ciência do Solo, Viçosa, MG, v. 23, n. 1, p. 53 58, jan./mar. 1999.

MILLER, R. M.; JASTROW, J. D. The application of VA Mycorrhizae to ecosystem restoration and reclamation. In: ALLEN, M. F. (Ed.). Mycorrhizal functioning. New York: Chapman and Hall, 1992. p. 438-467.

RAMAN, N.; NAGARAJAN, N.; GOPINATHAN, S.; SAMBANDAN, K. Mycorrhizal status of plant species colonizing a magnesite mine spoil in India. Biology and Fertility of Soils, Heidelberg, v. 16, n. 1, p. 76-78, 1993.

SCHENCK, N. C.; PÉREZ, Y. Manual for the identification of VA mycorrhizal fungi. Gainesville: University of Florida, 1987. 242 p.

SIQUEIRA, J. O.; COLOZZI-FILHO, A.; OLIVEIRA, E. de. Ocorrência de micorrizas vesicular-arbuscular em agro e ecossistemas do Estado de Minas Gerais. Pesquisa Agropecuária Brasileira, Brasília, v. 24, n. 12, p. 1499 1506, dez. 1989.

SMITH, S. E.; READ, D. J. Mycorrhizal symbiosis. 2nd ed. London: Academic, 1997. 605 p.

SOUZA, F. A. de; GUERRA, J. G. M. Emprego da técnica do número mais provável (NMP) no estudo de 
populações de fungos micorrízicos arbusculares (FMAs). Seropédica: Embrapa-CNPAB, 1998. 34 p. (Circular Técnica, 2).

WALLAND, M. E.; ALLEN, E. B. Relationships between VA mycorrhizal fungi and plant cover following surface mining in Wyoming. Journal of Range Management, Denver, v. 40, n. 3, p. 271-276, May 1987.

WARNER, N. J.; ALLEN, M. F.; MacMAHON, J. A. Dispersal agents of vesicular-arbuscular mycorrhizal fungi in a disturbed arid ecosystem. Mycologia, New York, v. 79 , p. 721-730, 1987.

WHITE, J. A.; MUN, L. C.; WILLIAMS, S. E. Edaphic and reclamation aspects of vesicular-arbuscular mycorrhizal in Wyoming Red Desert soils. Soil Science Society of America Journal, Madison, v. 53, n. 1, p. 8690, Jan./Feb. 1989.

ZONTA, E. P.; MACHADO, A. A.; SILVEIRA JÚNIOR, P. Sistemas de análise estatística para microcomputadores (SANEST). Pelotas: UFPel, 1984. 151 p. 